\title{
EL PRINCIPIO DE SUBSIDIARIEDAD EN LA LEGISLACION TURISTICA DE URUGUAY
}

\author{
DR. HUGO FERREIRA ARIZAGA ${ }^{1}$ \\ Profesor Adjunto de Derecho del Turismo (FDER) \\ Profesor Asistente de Legislación Turística (FHUCE) \\ Universidad de la República (UdelaR, Uruguay)
}

\section{Resumen}

En este capítulo proponemos analizar el principio de subsidiariedad en las actividades turísticas, sus antecedentes, fundamentación y, en especial, las características que presenta en el Derecho positivo uruguayo.

La metodología utilizada es jurídica, mediante el relevamiento y análisis del Derecho comparado, normas constitucionales, legales y reglamentarias, así como también de la doctrina en la materia.

Palabras clave: Turismo, Estado, subsidiariedad, prestadores de servicios turísticos.

Abstract

In this chapter we propose to analyze the principle of subsidiarity in tourism activities, its background, foundation and, especially, the characteristics that it presents in Uruguayan positive law.

The methodology used is legal, through the survey and analysis of comparative law, constitutional, legal and regulatory, as well as doctrine in the matter.

Key words: Tourism, State, subsidiarity, tourism service providers.

\section{INTRODUCCION}

\subsection{Marco normativo nacional}

La Constitución Nacional de 1967, en su parte dogmática, se refiere a los derechos fundamentales y garantías individuales, estableciendo los principios y las bases del Estado uruguayo como persona jurídica (democrático, republicano, laico).

En la parte orgánica se establece la estructura del Estado, las competencias de sus principales órganos, el régimen de la función pública y las relaciones entre la Administración y los ciudadanos.

El art. 7 expresa "Los habitantes de la República tienen derecho a ser protegidos en el goce de su vida, honor, libertad, seguridad, trabajo y propiedad. Nadie puede ser privado de estos derechos sino conforme a las leyes que se establecieren por razones de interés general".

${ }^{1}$ hhferre@vera.com.uy 
Otras disposiciones constitucionales garantizan la libertad de dedicarse a la industria, el comercio y otras actividades lícitas, las libertades de enseñanza, de cultos, de asociación y reunión, la protección del derecho al trabajo, la libertad sindical y el derecho de huelga.

De acuerdo al art. 10“Las acciones privadas de las personas que de ningún modo atacan el orden público ni perjudican a un tercero, están exentas de la autoridad de los magistrados. Ningún habitante de la República será obligado a hacer lo que no manda la ley, ni privado de lo que ella no prohíbe".

En consecuencia, el principio es la libertad del individuo en la esfera privada, con la salvedad de los límites que el legislador puede imponer por razones de interés general, o cuando sus acciones pueden afectar al orden público o a terceros.

En el mismo sentido rige el principio de la autonomía de la voluntad, con excepciones que obedecen a razones de orden público y deben estar previstas a texto expreso.

Es el caso de las Leyes de Turismo $\left(\mathrm{N}^{\circ} 19253\right)$ y de Relaciones de Consumo $\left(\mathrm{N}^{\circ}\right.$ 17250), ambas de orden público.

Por el contrario, en la Administración Pública es de aplicación el principio de especialidad de las personas jurídicas, ya que solamente pueden hacer aquello que les está permitido, actuando dentro del límite de sus respectivas competencias y para el cumplimiento de sus cometidos.

Es el caso del art. 190 de la Carta, que regula el funcionamiento de órganos dotados de distintos grados de autonomía y descentralización funcional, según el cual“Los Entes Autónomos y los Servicios Descentralizados no podrán realizar negocios extraños al giro que preceptivamente les asignen las leyes, ni disponer de sus recursos para fines ajenos a sus actividades normales".

Por tanto la Ley establece un marco dentro del cual estos órganos deben realizar sus actividades, sin exceder los límites que le son señalados por la normativa, así como destinar los recursos materiales que se les asigna para alcanzar, exclusivamente, los fines para los que fueron creados.

\subsection{Los cometidos del Estado}

Los cometidos estatales son los objetivos que persigue el Estado como persona jurídica y que puede alcanzar mediante el ejercicio de las funciones a su cargo.

Se establece así una relación de medio a fin entre ambos.

La función es un instrumento para el logro de estos cometidos, y debe ser cumplida por los órganos estatales en el ejercicio de sus atribuciones. De esta forma existe una estrecha relación entre los conceptos de atribución, competencia, función y cometidos.

La doctrina uruguaya distingue entre cometidos esenciales, servicios públicos, servicios sociales, participación del Estado en la actividad privada y regulación de la actividad privada.

Los cometidos esenciales son aquellos que solamente el Estado puede asumir, como la seguridad interna, la defensa nacional y conducción de las relaciones exteriores. No se conciben en manos de los particulares, ya que por su esencia son estatales. 
Por su parte en los servicios públicos, si bien existen intereses generales en juego, su prestación puede estar a cargo del Estado o de los particulares mediante concesiones, en un régimen de Derecho Público.

La concesión es un contrato celebrado entre el Estado y un particular (persona física o jurídica, nacional o extranjera), por el cual este último se obliga a la prestación de un servicio o la realización de una obra, por su cuenta y riesgo, bajo el control del Estado en la ejecución de los mismos ${ }^{2}$.

Marienhoff define al servicio público como "toda actividad de la Administración Pública o de los particulares o administrados, que tienda a satisfacer necesidades o intereses de carácter general cuya índole o gravitación, en el supuesto de actividades de los particulares o administrados, requiera el control de la autoridad estatal".

Algo similar ocurre con los servicios sociales que, a diferencia de los servicios públicos y más allá de los controles sobre sus actividades, no requieren de una concesión por el Estado.

En opinión de Sayagués Laso los servicios públicos y los servicios sociales deben prestarse en forma regular, continua e ininterrumpida, en buenas condiciones de funcionamiento y en igualdad de condiciones.

Cassinelli Muñoz sostiene que en ambas clases de servicios hay un grupo individualizable de usuarios; este es el caso del transporte público de pasajeros, la enseñanza, la salud o la seguridad social.

Esto no ocurre con los cometidos esenciales del Estado.

Para Rotondo "En caso de que el servicio público se cumpla por particulares, el Estado aparece con el rol regulador y de control como gerente del interés general, expresión constitucional uruguaya del bien común".

Luego dice "El prestador privado del servicio público -por cierto - seguirá siendo tal y en su organización empresarial se regirá por el Derecho privado, sin perjuicio de que la actividad a su cargo se tiña de las reglas del Derecho público".

Pezzutti señala que es en los servicios sociales donde se manifiesta con mayor intensidad el principio de subsidiariedad, y allí el Estado coadyuva al impulso privado para atenuar las insuficiencias del sistema y permitir a determinados grupos de personas el acceso a ciertos bienes o servicios que de otra forma les estarían vedados.

En este sentido Delpiazzo distingue entre servicios esenciales, servicios públicos y servicios de libre prestación por los particulares.

Con respecto a estos últimos dice "En tercer lugar, bajo el rótulo de servicios de libre prestación, se engloban una serie de actividades diversas que tienen como común denominador la viabilidad de ser desenvueltos por particulares en ejercicio de un derecho propio... Los principios que rigen esta categoría de servicios son los de libertad y subsidiariedad".

El autor distingue, a su vez, tres tipos de servicios de libre prestación:

${ }^{2}$ Delpiazzo (2015). 
“a) los servicios sociales, a los cuales ya se hizo referencia;

b) las actuaciones estatales en el campo de la actividad privada; y

c) las demás actividades de interés público".

Finalmente, mediante la regulación de la actividad privada el Estado establece las reglas de actuación, realiza controles sobre su cumplimiento y tiene el poder de sancionar infracciones.

Este cometido se cumple mediante el ejercicio de las funciones clásicas del Estado: constituyente, legislativa, ejecutivo- administrativa y jurisdiccional.

Para Sayagués Laso “cabe afirmar que uno de los cometidos fundamentales del Estado es la regulación de la actividad privada mediante normas, dictadas corrientemente por el órgano legislativo. Dicho cometido se cumple con la sola emisión de la norma legal. Dictada ésta, los particulares deben ajustar su conducta a las prescripciones establecidas por el legislador".

El rol del Estado comprende además la planificación, la gestión, el estímulo a los particulares y la coordinación de sus órganos entre sí y con aquellos.

En opinión de Velasco González la planificación "es un proceso ordenador que trata de definir líneas de acción que permitan conseguir objetivos fijados previamente. El aspecto formal de estos procesos cambia en el tiempo, imponiéndose ideas o modas que provienen de diferentes campos, en especial del mundo de la gestión empresarial, pero la función es siempre la misma: los planes son un instrumento que, de manera tentativa, tratan de modificar algún aspecto de la realidad actual mediante el diseño de un conjunto de acciones".

\section{EL PRINCIPIO DE SUBSIDIARIEDAD}

\subsection{Antecedentes $y$ fundamento}

Durán Martínez ${ }^{3}$ señala que el principio de subsidiariedad se origina en la Doctrina Social de la Iglesia Católica.

De acuerdo a este principio el Estado no puede realizar aquellas actividades que los individuos o las comunidades intermedias pueden hacer con su propio esfuerzo, o que no puedan serles confiadas sin "un grave perjuicio o peligro para la colectividad".

Este concepto se remonta, a la vez, al pensamiento de Santo Tomás.

En la Encíclica Quadragesimo Anno el Papa Pío XI expresa “... como no se puede quitar a los individuos y darle a la comunidad lo que ellos pueden realizar con su propio esfuerzo e industria, así tampoco es justo, constituyendo un grave perjuicio y perturbación del recto orden, quitar a las comunidades menores e inferiores lo que ellas pueden hacer y proporcionar y dárselo a una sociedad mayor y más elevada...".

McCadden señala que, posteriormente, Juan XXIII aplica este concepto no sólo al papel de la autoridad pública dentro de la economía, sino también a cuestiones de ayuda

\footnotetext{
3 “Turismo. Algunos aspectos del régimen administrativo nacional". Estudios de Derecho Administrativo. Segundo Curso/5. ACALI Editorial, Montevideo, 1979.
} 
regional por el gobierno central ${ }^{4}$, y a su vez extiende la subsidiariedad a los asuntos internacionales (Pacem in Terris, 1963).

El Tratado de la Unión Europea (Maastricht,1992) recoge el principio de subsidiariedad con carácter general y en estos términos: "En los ámbitos que no sean de su competencia exclusiva, la Comunidad intervendrá, conforme al principio de subsidiariedad, sólo en la medida en que los objetivos de la acción pretendida no puedan ser alcanzados de manera suficiente por los Estados miembros y, por consiguiente, puedan lograrse mejor, debido a la dimensión o a los efectos de la acción contemplada, a nivel comunitario. Ninguna acción de la Comunidad excederá de lo necesario para alcanzar los objetivos del presente Tratado" (art. 3 A).

Con anterioridad, en el Acta Única Europea de 1987 este principio se aplicaba solamente a la política de medio ambiente.

Art. 130 R.4.: "La Comunidad actuará, en los asuntos de medio ambiente, en la medida en que los objetivos contemplados en el apartado 1 puedan conseguirse en mejores condiciones en el plano comunitario que en el de los Estados miembros considerados aisladamente. Sin perjuicio de determinadas medidas de carácter comunitario los Estados miembros asumirán la financiación y la ejecución de las demás medidas".

En este punto Mc Cadden distingue entre los principios de subsidiariedad, efectividad y atribución de competencias; en la subsidiariedad la competencia de la esfera inferior tiene un valor en sí misma, mientras que en el principio de efectividad, la esfera inferior padece un menoscabo en la ejecución de su competencia, pues es sustituida.

Con respecto a la atribución de competencias sostiene que en el Tratado de Maastricht la subsidiariedad no se confunde con el principio de atribución de competencias, aunque la técnica de devolución de competencias presente un carácter subsidiario.

Por su parte Francisco E. Cerro afirma que el principio de subsidiariedad es un principio jurídico, no técnico, fundado en la justicia y en el derecho de asociarse.

En su opinión "los tiempos exigen un Estado fuerte pero limitado en su intervención. Es imprescindible el marco jurídico y político para hacer posible y fructífera la libertad, pero con solidaridad para la consecución del bien común."

Rodríguez Cairo considera que el rol subsidiario del Estado presenta dos aspectos fundamentales: 1) evita que el estado se sobredimensione a través del incremento del gasto público, y 2) que se destinen los escasos recursos públicos a la producción de bienes y servicios que pueden ser provistos por los particulares.

Por lo tanto el rol del Estado es fomentar, estimular, coordinar y complementar el esfuerzo privado.

La subsidiariedad puede presentarse de dos formas: vertical u horizontal.

Es vertical - dice este autor - cuando refiere a las relaciones entre un órgano nacional o central y otros órganos, locales o regionales, donde el primero solamente puede intervenir en aquellas cuestiones que no sean de competencia de los segundos.

\footnotetext{
${ }^{4}$ En Mater et Magistra (1961).
} 
Es horizontal cuando trata de relaciones entre el Estado y los ciudadanos, a quienes se les garantiza libre determinación y autonomía; la intervención estatal se reduce aquí a lo esencial $^{5}$.

Para Frosini "el principio de subsidiariedad ha venido a situarse en la cúspide, importantísima en un Estado de democracia pluralista, entre la esfera de la descentralización institucional y la de la autonomía de la social, en cuanto principio inspirador de un proceso de socialización de los poderes públicos".

Según Quintana Benavídes además del principio de subsidiariedad deben considerarse los principios de solidaridad, eficiencia y eficacia como orientadores de la actividad del Estado.

La solidaridad determina cuáles son las prioridades de su intervención (acción directa del Estado), mientras que la eficiencia supone utilizar los recursos públicos para satisfacer las tareas de manera que se logren sus fines al menor costo. Esto es, responsabilidad de los funcionarios públicos.

De esta forma -sostiene- "Eficiencia sería, entonces, la correcta ordenación de los medios para la consecución de un fin".

\subsection{Reseña del Derecho comparado}

Distintas legislaciones nacionales han recogido el principio de subsidiariedad en la actividad turística, así como la promoción y el estímulo a la participación privada en el sector.

En Colombia, la Ley $\mathrm{N}^{\circ} 1558$ del10 de Julio de 2012 recoge el principio de la libertad de empresa, por el cual el turismo es una industria de servicios "de libre iniciativa privada, acceso libre y libre competencia" (art. $3^{\circ} .5$ ).

La Ley de Turismo de Ecuador ( $\mathrm{N}^{\circ}$ 97-2002) reconoce a la iniciativa privada como un pilar fundamental del sector, para la inversión directa, la generación de empleo y la promoción nacional e internacional (art. 3).

En el mismo sentido el art. 4 dispone que la política estatal debe tener entre sus objetivos el reconocer que la actividad turística corresponde a la iniciativa privada y comunitaria o de autogestión, y que al Estado le compete fomentar y promover un producto turístico competitivo.

En Chile, conforme a la Ley $\mathrm{N}^{\circ} 20423$, el Estado impulsará la asociatividad de los agentes privados y establecerá programas para el fortalecimiento de las empresas, especialmente las de menor tamaño (art. 4).

La Ley Federal de Turismo de México provee el estímulo a la inversión nacional y extranjera en el turismo, así como propiciar mecanismos para la participación privada en el cumplimiento de sus objetivos (art. 2, puntos VII y VIII).

La Ley General de Turismo N 29408 del Perú dispone que el Estado promueve la inversión privada en el turismo para la generación de empleo, la mejora de la calidad de vida

\footnotetext{
${ }^{5}$ Tribunal Constitucional, Perú (2003): Exp .N. ${ }^{\circ} 0008-2003-A I / T C$.
} 
de la población local y la transformación de recursos naturales en productos turísticos sostenibles (art. 3.4).

En la Ley española $\mathrm{N}^{\circ} 48 / 1963$ de 8 de Julio, sobre competencia en materia turística, se estableció que corresponde al Ministerio de Información y Turismo "la ordenación y vigilancia de toda clase de actividades turísticas, así como también el directo ejercicio de éstas en defecto o para estímulo y fomento de la iniciativa privada".

La Ley de Turismo de Andalucía $\mathrm{N}^{\circ}$ 13/2011tiene como objeto y finalidad, entre otros, "El estímulo del asociacionismo empresarial y profesional y la mejora de la competitividad del sector turístico, basada en la incorporación estratégica de criterios de calidad, la profesionalización de los recursos humanos, la innovación y la sostenibilidad" (art. $1^{\circ}$, lit. c).

Por su parte la Ley $\mathrm{N}^{\circ} 13 / 2002$ de Turismo de Cataluña (art. $3^{\circ}$ ), establece entre las finalidades de las administraciones públicas y de los sujetos turísticos:

“d) Incrementar las corrientes turísticas, tanto las interiores como las exteriores, con especial atención al turismo de calidad, e impulsar la actividad turística como sector estratégico de la economía y de la ocupación y como factor clave para el equilibrio territorial y la prosperidad de Cataluña.

e) Impulsar el desarrollo de nuevos productos, actividades y ámbitos de interés turístico y potenciar la calidad y la vitalidad de los destinos, las denominaciones y las marcas turísticas".

A su vez, el objeto de la Ley de Turismo del País Vasco $\mathrm{N}^{\circ} 13 / 2016$ (art. $1^{\circ}$ ), es"la regulación de la actividad turística en Euskadi, la ordenación y disciplina del sector turístico, así como el establecimiento de los principios y criterios de actuación de las administraciones turísticas".

Con este fin el art. $4^{\circ}$ establece, entre otros principios rectores:

“o) La configuración de un marco normativo que fomente la modernización del sector, favoreciendo la innovación y la calidad.

p) La vigilancia y la persecución de las actividades que contravengan la regulación normativa del sector turístico.

q) La adopción de las medidas precisas para facilitar una adecuada profesionalización de las personas que trabajan en el sector turístico.

r) El impulso y apoyo al asociacionismo empresarial en el sector".

\section{EL PRINCIPIO DE SUBSIDIARIEDAD EN URUGUAY}

\subsection{La normativa turística nacional}

Labaure Aliseris sostiene que en Uruguay las bases constitucionales, si bien no lo mencionan expresamente, recogen este principio en cuanto establecen la intervención subsidiaria del Estado en la libertad de trabajo y de empresa, el cuidado y la educación de los hijos en situaciones de abandono, la atención de la salud a quien no pueda asistirse y el estímulo a la inversión privada para la construcción de viviendas, entre otros. 
En opinión de Cagnoni "El Estado no debe absorber ni destruír a los miembros del cuerpo social sino prestarles ayuda o auxilio, lo que comporta en sí mismo una doble vertiente, negativa y positiva mutuamente implicadas".

La Ley de Turismo N ${ }^{\circ} 19253$ y su antecedente, el Decreto- Ley 14335, declaran al turismo como una actividad de interés público y como factor de desarrollo económico, social y cultural para el país.

Los principios que rigen a las actividades turísticas están consagrados en el art. 3 de la nueva Ley, entre los cuales se destaca el principio de subsidiariedad del Estado en la prestación de servicios turísticos.

Los otros principios que menciona esta norma son los de calidad, cooperación, competitividad, sostenibilidad, accesibilidad, tuitivo y holístico.

De acuerdo al Art. 3, literal G): "La prestación de servicios turísticos corresponde, de principio, a la actividad privada, sin perjuicio de que el Estado podrá participar directamente en dicha prestación cuando los particulares no quieran o no puedan prestarla, o cuando así lo impongan razones de interés general".

Este principio también fue recogido en el Decreto Ley 14335 del año 1974, en términos similares a la Ley 19253.

“Al Estado corresponde la orientación, el estímulo, la promoción, la reglamentación, la investigación y el control del turismo y de las actividades y servicios directamente conectados al mismo. La prestación, explotación y el desarrollo de actividades y servicios calificados como turísticos corresponden a la actividad privada.

No obstante el Estado, por razones de orden público, o cuando considere necesaria la explotación de actividades y servicios turísticos que los particulares no quieran o no puedan asumir, la tomará a su cargo".

Pues bien: ¿Cuál es el significado del término "subsidiariedad” en la Ley?

De acuerdo a la norma al Estado le compete el fomento, la regulación y fiscalización de la actividad y podrá tomar a su cargo la explotación de servicios turísticos solamente cuando los particulares no puedan o no quieran hacerse cargo de ella, o cuando medien razones de interés general.

Esto implica que en caso de existir desinterés por parte de los privados en prestar un determinado servicio turístico, de no poder asumir su prestación o si median razones de interés general, el Estado podrá hacerse cargo de ello; así como también puede explotarlos en concurrencia con la actividad privada.

Del enunciado del principio en cuestión se desprende que para la Ley, los particulares tienen la prioridad en la explotación de estas actividades y que a su vez, el Estado tiene la facultad de asumirla cuando se configuren alguno de los presupuestos previstos en la norma.

Se trata así de una facultad, no de un deber de la Administración.

Con esto no se configura una desprotección del orden público, sino que consiste en dejar la iniciativa y explotación de ciertas actividades en manos de los particulares. ${ }^{6}$

\footnotetext{
${ }^{6}$ Pezzutti (2006).
} 
El art. 50 de la Constitución Nacional establece que las actividades comerciales o industriales monopólicas o trustificadas, a cargo de particulares, estarán bajo el control del Estado. En nuestro Derecho no hay una prohibición -legal o constitucional- del Estado de intervenir en ciertas actividades económicas, como ocurre en otros sistemas jurídicos.

Por el contrario, el Estado puede prestar servicios de forma monopólica o en libre concurrencia con los particulares; tal es el caso de las empresas del dominio comercial e industrial del Estado, que deben estar organizadas bajo la forma de Entes autónomos o de Servicios descentralizados.

El art. 188 de la Constitución Nacional habilita la conformación de las denominadas "sociedades de economía mixta" de dos maneras.

Una de ellas es la mediante la participación de capitales privados en la constitución o ampliación del capital de los Entes autónomos y Servicios descentralizados.

Esta participación debe ser autorizada por medio de una ley, aprobada por mayoría especial (3/5) de los componentes de cada Cámara, y en ningún caso los aportes de capitales privados pueden superiores a los del Estado.

La otra forma es la participación del Estado en empresas formadas por aportes obreros, cooperativos o capitales privados, dedicadas a actividades industriales, agropecuarias o comerciales, mediando el libre consentimiento de la empresa y en las condiciones acordadas previamente.

Dicha participación deberá ser autorizada por medio de una ley aprobada por la mayoría absoluta de componentes de ambas Cámaras, asegurando la participación del Estado en la dirección de la empresa.

Un ejemplo de esta última modalidad es el caso de la ex aerolínea nacional PLUNA $(1936)^{7}$, que en sus orígenes fue una empresa privada y a partir de 1995 contó con participación minoritaria de capital estatal, hasta el cese de sus operaciones en el año 2012.

Por otra parte, cabe citar la Ley de Turismo en cuanto autoriza al Ministerio de Turismo a crear fondos cofinanciados con particulares hasta un máximo del $70 \%$ de aportes públicos, destinados a atender proyectos, programas y actividades de distinta naturaleza en el sector.

Estos fondos serán administrados por dicho Ministerio y en ningún caso los aportes privados pasarán a tener el carácter de fondos públicos (art. 27).

\subsection{Cometidos y atribuciones del Poder Ejecutivo y del Ministerio de Turismo}

¿Cómo se lleva a la práctica el principio de subsidiariedad?

A continuación citaremos de las algunas disposiciones de la Ley uruguaya de Turismo de las que surgen previsiones y mecanismos sobre este punto.

El art. 6 de la Ley 19253 establece que son cometidos del Poder Ejecutivo en la materia turística, entre otros:

${ }^{7}$ En sus inicios "Primeras Líneas Uruguayas de Navegación Aérea", luego denominada "PLUNA Primeras Líneas Aéreas Uruguayas S.A.” 
“A) Fijar y dirigir la política nacional de turismo,

B) Promover el desarrollo de la actividad turística a nivel nacional, regional e internacional, trazados..."

C) Facilitar la aplicación de capitales a la actividad dentro del marco de los objetivos

De acuerdo al art. 7 de la Ley son competencias del Poder Ejecutivo en la materia turística, entre otras:

“A) Aprobar el Plan de Desarrollo Estratégico de Turismo Nacional, así como otros proyectos y programas específicos;

E) Crear mecanismos de promoción de inversiones en materia turística;

G) Otorgar concesiones en bienes de propiedad del Estado, con fines de explotación turística, así como desarrollar acciones tendientes a la mejora de la infraestructura turística y obras públicas complementarias;

L) Establecer los lineamientos generales de los requisitos que serán exigidos, dentro del marco de la presente ley, a los particulares que desarrollen actividades dentro del sector, sin perjuicio de lo dispuesto en el literal D) del artículo $8^{\circ}$ de la presente ley".

Con respecto a las atribuciones del Ministerio de Turismo cabe destacar el art. 8, en cuanto dispone:

“A) El fomento del turismo mediante el desarrollo de actividades propias, el estímulo de la actividad de los particulares o similar;

D) Establecer, dentro del marco de la presente ley y de los reglamentos que se dicten, las condiciones y requisitos a exigir de aquellas personas físicas o jurídicas que desarrollen alguna de las actividades reguladas por esta ley;

E) La regulación, en los mismos términos del literal D), de las actividades y prestaciones directa o indirectamente vinculadas con el turismo;

H) El control de los prestadores, de las prestaciones y del cumplimiento de las disposiciones legales y reglamentarias que rigen la materia”.

Hemos visto que, conforme al principio de subsidiariedad, el Estado fomenta la explotación de las actividades turísticas por parte de los particulares y que puede decidir asumirlas solamente en ciertos casos (desinterés, imposibilidad de su prestación por parte de aquellos, o si existen razones de interés general).

También se ha dicho que la subsidiariedad está estrechamente vinculada a los principios de efectividad y eficacia.

Ahora bien: ¿cómo se puede lograr que la prestación de servicios turísticos por los particulares sea eficaz y adecuada?

En tal sentido es fundamental el control estatal sobre las actividades de los prestadores de servicios; esto es tan necesario como el estímulo mismo a la explotación de la actividad.

En este aspecto cobra importancia la obligatoriedad de la inscripción previa en el Registro de Prestadores de Servicios Turísticos del Ministerio de Turismo, requisito que en la actualidad alcanza a todos, en forma previa al inicio de sus actividades (arts. 10 y 11). 
En el mismo sentido lo es la exigencia de contratar seguros de responsabilidad civil y de constituir garantías de funcionamiento para atender al pago de multas, condenas resultantes de sentencias judiciales firmes y de otras obligaciones (art. 13).

Con respecto a la relación contractual con los turistas se destaca el deber de informar al cliente sobre todos los términos y condiciones de los servicios ofrecidos, la obligación de prestarlos en las mejores condiciones posibles, así como el deber de abstenerse de contratar o tercerizar sus servicios con prestadores considerados como "irregulares" por la Ley.

De acuerdo al principio de calidad "Los prestadores turísticos tenderán a adecuar sus prestaciones dentro de estándares de calidad de reconocimiento internacional que posibiliten, en el futuro, mecanismos de certificación de las mismas" (art. 3, literal C de la Ley).

En este aspecto el art. 16, in fine dispone que el Ministerio de Turismo "Asimismo, facilitará, cuando lo estime pertinente, la obtención de beneficios e incentivos para aquellos prestadores de servicios turísticos que se encuentren en situación de cumplimiento de los requisitos legales y reglamentarios y encaminados a la obtención de la certificación de la calidad de sus procesos y actividades".

A su vez, la Dirección Nacional de Turismo puede requerir información alos prestadores de servicios turísticos con fines estadísticos y registrales, la actualización de datos para un adecuado control de la actividad, así como ordenar inspecciones en los establecimientos con el fin de constatar el cumplimiento de las disposiciones legales y reglamentarias (art. 9).

\section{CONSIDERACIONES FINALES}

En Uruguay son muy variados los servicios turísticos a cargo de prestadores privados (agencias de viajes, alojamientos, guías, transportes, arrendadoras de vehículos, gastronomía, entre otros).

En ciertos casos el Estado es prestador directo de servicios a los turistas, como ocurre en los centros termales del Litoral Oeste (Salto y Paysandú), en concurrencia con la oferta de establecimientos privados.

A su vez, en el ramo de hotelería se han dado en concesión establecimientos tradicionales, como el Argentino Hotel de Piriápolis (Maldonado) yel Hotel Casino Carrasco (Montevideo).

En el Decreto - Ley 14335, aprobado en 1974 para la regulación de las actividades turísticas, fue consagrado el principio de subsidiariedad del Estado en la explotación de servicios turísticos.

El mismo criterio ha seguido la nueva Ley de Turismo del año 2014, junto a otros principios rectores de la actividad que hemos mencionado con anterioridad.

En ambos casos se han fijado los lineamientos generales para la actividad, dejando a cargo del Poder Ejecutivo el dictado de las normas reglamentarias para su aplicación y ejecución. 
Son numerosas las normas aprobadas, atendiendo a la especificidad de las actividades, como es el caso de los establecimientos de turismo rural, prestadores de servicios de turismo aventura, organizadores profesionales de congresos, agencias de viajes, etc.

El fundamento de la subsidiariedad radica en que el Estado se dedique al cumplimiento de sus cometidos, dejando en manos de los particulares la explotación de ciertas actividades económicas que éstos pueden asumir.

Para ello es necesario que el Estado establezca reglas claras, estimule la inversión y ofrezca seguridad jurídica en los aspectos administrativos, comerciales, tributarios y laborales.

A vía de ejemplo cabe citar la Ley 16906 (1998), para la promoción y protección de las inversiones en el país, que ofrece beneficios fiscales a los inversores nacionales y extranjeros amparados al régimen de la misma, asegurándoles la igualdad de trato, la libre transferencia de utilidades al exterior, garantizando además la no interferencia del Estado en sus emprendimientos.

Sin embargo, no se trata solamente de dar impulso a la iniciativa privada, sino también de controlar efectivamente el cumplimiento de la normativa y exigirles la prestación de servicios en condiciones adecuadas para alcanzar niveles de calidad y competitividad en el sector turístico.

Por otra parte es indispensable asegurar al turista, destinatario final de los servicios turísticos, el respeto y la protección efectiva de sus derechos.

En este sentido la Ley de Relaciones de Consumo (2000) consagra los derechos básicos del consumidor, establece un sistema basado en la buena fe, la prohibición de cláusulas abusivas y prácticas desleales en la contratación y prevé mecanismos para la solución de conflictos entre los proveedores de servicios y los usuarios.

Con respecto a esto último, la nueva Ley de Turismo creó los Centros de Conciliación Turística, que funcionarán en el Ministerio de Turismo, para la solución de los conflictos planteados entre prestadores de servicios turísticos y turistas $\mathrm{y}$, excepcionalmente, de los prestadores entre sí.

En definitiva, consideramos que la subsidiariedad del Estado en la explotación de las actividades turísticas es una solución adecuada, siempre y cuando se den las condiciones fácticas e implementen los instrumentos necesarios para asegurar la calidad y efectividad de los servicios encomendados a los particulares, así como la salvaguarda de los derechos de los turistas.

\section{BIBLIOGRAFIA}

CAGNONI, J.A.:"Estudios sobre el Estado Democrático y Social de Derecho”. Barreiro y Ramos, Montevideo, 1989.

CASSINELli MUÑOZ, H.: "Derecho Público" Edición actualizada. FCU. Montevideo, 2009.

CERRO, F. E.: "El principio de subsidiariedad en el siglo XXI". Disponible en www.acaderc.org.ar.Doctrina/artículos.pdf, 2000. 
DELPIAZZO, C.E.: "Proyección de dos clásicos franceses del Derecho Administrativo" en Revista de la Facultad de Derecho $N^{o}$ 32. Enero-Junio 2012.Montevideo, p. 143-168.

DELPIAZZO, C.E.: "Promoción y captación de la inversión privada en el sector público" en "Regulación de la actividad privada". FCU. Montevideo, 2015. p. 109-125.

DURÁN MARTÍNEZ, A.: "Turismo. Algunos aspectos del régimen administrativo nacional". Estudios de Derecho Administrativo. Segundo Curso/5.ACALI Editorial, Montevideo, 1979.

FROSINI, T. E.: "SUBSIDIARIEDAD Y CONSTITUCIÓN" en Revista de Estudios Políticos (Nueva Época) Núm. 115. Enero-Marzo 2002, p. 7-26.Disponible en https://dialnet.unirioja.es, 2002.

LABAURE ALISERIS, C.: "Estado social: del intervencionismo a la subsidiariedad" en Anuario de Derecho Administrativo Tomo VII. FCU. Montevideo,1999, p. 59-64.

MAC CADDEN, C.: "El principio de subsidiariedad y el Tratado de Maastricht" en ESTUDIOS filosofía-historia-letras. Otoño 1992 (ITAM, México),1992.

Disponible en www.biblioteca.itam.mx/estudios/estudio/letras30/notas2/sec_12.html.

MARIENHOFF, M. S.: "Tratado de Derecho Administrativo" Tomo II No 306.Buenos Aires, Argentina, 1981.

PEZZUTTI, M.:"Algunas consideraciones sobre la regulación administrativa de las actividades turísticas" en "Derecho del Turismo". FCU. Montevideo, 2006, p. 11-35.

QUINTANA BENAVIDES, A.: "El principio de subsidiariedad" en Revista de Derecho Público. Edición Especial. Facultad de Derecho. Universidad de Chile, 2014, p.125-136.

RODRÍGUEZ CAIRO, V.: "Principio de subsidiariedad económica del Estado en la Constitución Política del Perú" en QUIPUKAMAYOC Revista de la Facultad de Ciencias Contables. Vol. $21 \mathrm{~N}^{\mathrm{o}}$ 40.Universidad Nacional Mayor de San Marcos (UNMSM).Lima, 2013, p. 113-122.

ROTONDO, F.: "Los principios de los servicios públicos" en Revista CADE Doctrina \& Jurisprudencia Tomo XXIX. Montevideo, 2014, p. 57-70.

SAYAGUÉS LASO, E.: "Tratado de Derecho Administrativo" Tomo I,5 edición. Clásicos Jurídicos Uruguayos, FCU. Montevideo, 1987.

VELASCO GONZALEZ, M.: "La incorporación de ideas en las políticas públicas. El concepto de sostenibilidad en la política turística" en Revista de Análisis Turístico $\mathrm{N}^{\mathrm{o}} 10,2^{\circ}$ semestre 2010. Asociación Española de Expertos Científicos en Turismo (AECIT), p. 35-44.

\section{NORMATIVA CITADA}

Colombia. Ley de Turismo $N^{\circ}$ 1558. Diario Oficial N 48.487, 10 de Julio de 2012.

Chile. Ley $\mathrm{N}^{\circ} 20423$ Del sistema institucional para el desarrollo del turismo.

Publicación: 12 de Febrero de 2010.

Ecuador. Ley de Turismo N 97- 2002. Registro Oficial Suplemento 733,27 de

Diciembre de 2002. 
España. Ley $\mathrm{N}^{\circ}$ 48/1963 de 8 de Julio sobre competencia en materia turística. BOE Núm. 164, 10 de Julio de 1963.

España. Ley del Turismo de Andalucía N 13/2011.BOE Núm. 17, 20 de Enero de2012.

España. Ley N $\mathrm{N}^{\circ}$ 13/2002 de Turismo de Cataluña. BOE Núm. 169, 16 de Julio de 2002.

España. Ley N 13/2016 de Turismo del País Vasco. BOE Núm. 219, 10 de Septiembre de 2016.

México. Ley Federal de Turismo. Diario Oficial de la Federación, 31 de Diciembre de 1992.

Perú. Ley General de Turismo N² 29408 del 16 de Setiembre de 2009.

Unión Europea. Acta Única Europea. DOL 169, 29 de Junio de 1987.

Unión Europea. Tratado de Maastricht.DOC 191, 29 de Julio de 1992.

Uruguay. Constitución de la República. Diario Oficial, 2 de Enero de 1967.

Uruguay. Decreto Ley $N^{\circ}$ 14335. Ley de Turismo. Diario Oficial, 2 de Enero de 1975.

Uruguay. Ley $N^{\circ}$ 16906. Ley de Inversiones. Promoción Industrial. Diario Oficial, 20 de Enero de 1998.

Uruguay. Ley $\mathrm{N}^{\circ} 17250$. Relaciones de Consumo. Defensa del Consumidor. Diario Oficial, 17 de Agosto de 2000.

Uruguay. Ley $\mathrm{N}^{\circ}$ 19253. Regulación de la actividad turística. Diario Oficial, 9 de Septiembre de 2014. 